\title{
Blogging for Teaching and Learning: An Examination of Experience, Attitudes, and Levels of Thinking
}

\author{
Kun Li, Niamboue Bado, Jamie Smith, \& David Moore \\ Ohio University, United States
}

\begin{abstract}
Blogs have been widely used in education since their emergence. Educational researchers and practitioners have integrated blogs into teaching and learning in different subject areas, but does blog use encourage critical thinking? This paper presents a study, which explores peer commenting for critical thinking in blog writing. In order to discover blogging for skill development, survey method and focus group were employed in this study. Results of blog content analysis indicate levels of critical thinking remain constant with or without peer commenting. Based on the findings, recommendations are provided for effective use of blogs for instruction.
\end{abstract}

Keywords: Blogging; Critical thinking; Attitude; Experience; Pre-service teacher

\section{Introduction}

The Internet and Web 2.0 technologies offer students more choices and flexible learning opportunities. Lenhart, Simon, \& Graziano (2001) indicate that Internet usage by teens both inside and outside of the classroom is increasing. Considering all the potential benefits the Internet and Web 2.0 technologies could bring to students' learning, Hurlburt (2008) suggests that instructors should take advantage of the Internet by incorporating Web 2.0 tools in education. Specifically, "Internet and Web 2.0 technologies afford students opportunities to seek information, collect their own material, communicate, make meaning, and evaluate end products" (Nelson, Christopher, \& Mims, 2009, p. 81).

Blogs are one of the most popular Web 2.0 tools; many educators use them to improve learning. The interactivity of blogs is emphasized by researchers (Alexander, 2006; Scheidt, 2009). Williams and Jacobs (2004) suggest educators use blogs as platforms for peer review. Peer feedback appears to create a virtuous cycle, providing valuable information while improving students' attitudes toward blogging (Yang \& Chang, 2012).

Blogging appears to support reflective thinking (Good \& Whang, 2002; Xie, Ke, \& Sharma, 2007; Yang, 2009); however, studies on blogging and critical thinking skills are lacking (Sim \& Hew, 2010; Chu, Chan, and Tiwari, 2012). This exploratory study investigates peer commenting, blogs and critical thinking skills. As a result, strategies for using blogs in the classroom were provided.

These questions were asked to guide the study:

1. What are learners' attitudes toward blogging? 
2. What is the relationship between peer commenting and critical thinking?

3. What are some potential usages of blogs perceived by participants?

\section{Literature Review}

\section{Blogs}

Barger first used the term "weblog" in 1997 (Blood, 2000); Merholz shortened the term to 'blog' in 1999 (Loving, Schroeder, Kang, Shimek, \& Herbert, 2007). Stefanac (2006) defines a blog as an "easy to update website characterized by dated entries displayed in reverse chronological order" (p. 230). According to Scheidt (2009), blogging became popular after the opening of two commercial services, Livejournal.com and blogger.com, in 1999. These platforms made it easier for Internet users to create and maintain blogs.

Blogs are commonly used to gather information related to a particular topic; as personal journals to record information on life events; as course management tools; as assessment tools and as communication and interaction tools (Sim \& Hew, 2010). 'Simplicity' and 'interactivity' are two key elements that have contributed to blogs' popularity (Alexander, 2006; Scheidt, 2009). Any person with basic computer skills and an Internet connection can maintain a blog. Furthermore, blogs allow users to publish, archive and interact (Williams \& Jacobs, 2004). Participants interact in their roles as blog writers, readers and reviewers; they write entries and respond to criticism from peers (Pinkman, 2005).

\section{Attitudes Toward Blogging in Higher Education}

Various studies have attempted to investigate learners' attitudes toward the use of blogs in higher education (Coutinho, 2007; Ellison \& Wu, 2008; Halic, Lee, Paulus \& Spence, 2010; William \& Jacobs, 2004). William and Jacobs (2004) reported that a majority of MBA students at the Harvard Law School and Queensland University of Technology indicated a positive attitude toward the use of blogs in teaching and believed that the use of blogs contributed to their learning. Teachers and pre-service teachers also show a positive attitude toward the use of blogs in teaching and learning. Yang (2009) found that Taiwanese English as a Foreign Language (EFL) teachers appreciated the use of blogs for promoting critical thinking skills, reporting that the use of blogs for discussion was more effective than face-to-face discussion. Coutinho (2007) and Zeng and Harris (2005) obtained similar results.

Other studies have found that undergraduate students report that blogs contribute to building a sense of community and to better understanding learning content. Halic, Lee, Paulus and Spence (2010) found that the majority of the participants believed that blogs created a sense of community, which in turn enhanced their learning. Ellison and Wu (2008) conducted a study that investigated students' attitudes toward blogging in the classroom and its effect on comprehension. The results of the study indicated that the majority of the participants showed positive attitudes toward blogging. They reported that reading others' blogs contributed to a better understanding of the course content. Undergraduate students writing blogs during their internship perceived blogging as a knowledge sharing space positively (Chu, Kwan, \& Warning, 2012). 


\section{Blogging and Higher Level Thinking}

Different blogging styles can affect interactivity and critical thinking in a blogging context. Xie, Ke and Sharma (2010) conducted a study on the effect of peer-interaction styles on students' thinking. Results showed that when individuals started their blog posts as monologues, they were more likely to write longer posts than if they started them as questions. However, monologues generated fewer comments than questioning styles. Therefore, a questioning style was more likely to result in higher level of interactivity and critical thinking. According to Hurlburt (2008), students were less likely to comment on their peers' blogs if they were not required to do so. For that reason, Hurlburt suggested that instructors impose comment quotas and provide grading rubrics for evaluating blogs.

Several studies conducted in higher education have reported that blogs contribute to the development of critical thinking skills (Deng \& Yuen, 2011; Good \& Whang, 2002; Shoffner, 2008; Yang, 2009). Good and Whang (2002) claimed that blogging could be a useful tool to help pre-service teachers reflect on their experience and construct meanings; they found that pairing up pre-service teachers to blog and comment on one another's blogs was beneficial to both participants. Similarly, Shoffner (2008) argued that blogs could be invaluable tools for stimulating an informal reflective practice among pre-service teachers; the participants reported that interactive blogging helped them integrate reflective practices into their professional life. Yang (2009) argued that blog usage promoted critical thinking skills and builds a community of practice in pre-service EFL teacher training. Yang also noted that the majority of the posts were descriptive in nature; they became critical and reflective only after being challenged by the instructor. In addition, the majority of the participants did not find the comments useful. Some did not even read their peers' comments.

The effect of interactivity on critical thinking and reflective skills is not always positive. Xie, Ke and Sharma (2007) argued that interactivity could have a negative effect on reflective and critical thinking. The researchers investigated the effect of peer feedback on college students' reflective thinking skills. Results showed that peer feedback negatively affected students' reflective thinking skills. The researchers speculated that this was due to the poor quality of the comments made by peers.

In general, the results of the studies show that students have positive attitudes toward the use of blogs in education. Also, interactive blogging has been found to have an effect on learners' reflective and critical thinking, though the issue of whether the effect is positive or negative is still questionable. This study extends these efforts and provides guidance for implementing peer review strategies using blogs.

\section{Methodology}

\section{Research Design}

Based on the research questions, this study implemented a mixed methods approach to answer the research questions. Research question one and three are about participants' attitudes and perceptions. They will be addressed with open-ended questions in an online survey and a focus group which probed participants' about their experience using blogs in the study. Whereas research question two, addressing whether there is a difference on critical 
thinking levels in participants' blogs before and after peer commenting, will be answered by coding and comparing participants' blogs before and after peer commenting.

Eleven undergraduate students in a Midwest University in the United States participated in this study. All participants were teacher candidates enrolled in a technological application course. The study lasted for eight weeks of an academic quarter. Participants were introduced to blogs in week two and required to write at least one blog entry for each of the following weeks. Participants were instructed to relate their blog content to what they learned in class, including problems or issues they encountered as well as how they fixed the problems, and how they would apply the digital tools in their future classrooms. From week two to week five, participants were asked to write entries without reading or commenting on others' blogs. From week six to week nine, they were required to continue publishing blog entries each week in addition to reading and commenting on two peers' blogs each week.

\section{Data Sources}

Multiple strategies were used to collect data. Blog entries, an online survey and a focus group interview constitute the data triangulation to ensure the credibility of the study (Creswell, 2013).

Eight weeks of blog entries, completed by all eleven participants, were retrieved for analysis. Participants were given an online survey, which contained five items probing their technology skills and blogging experience before taking this class, eight items measuring their time spent on each blog entry, self-reported critical thinking on each blog, attitudes toward writing blog entries before and after being required to read and comment on their peers' blogs and selfreported reasons of the difference or no difference on levels of thinking before and after peer commenting. Two open-ended questions were included for participants to address how they intended to incorporate blogs in their future classrooms.

At the end of the last class in week ten, a focus group interview was conducted by the second author, who was not the instructor of the class. He asked participants questions on three major issues: whether there was a change in participants' attitudes toward blogging before and after peer review and commenting, and why, the blogging platforms they selected, and why, and how blogs could be utilized in their future classrooms.

\section{Data Analysis}

Different methods were used to analyze the data sources in order to address the research questions.

The total words of each blog entry were used to analyze whether participants wrote more when peer commenting was required. Weerkamp and de Rijke (2008) found that blog post length was a good predictor of quality. The average word counts of blogs before and after peer commenting were calculated for each student. Wilcoxon signed-rank test was used to measure the differences in medians between the blog entry word counts before and after peer commenting. Statistical Package for the Social Sciences (SPSS) version 17.0 was used to run the test. 
The Critical and Uncritical Thinking Indicator Method (CUTIM) developed by Newman, Webb, and Cochrane (1995) employs Garrison's (1992) five stages of critical thinking and Henri's (1991) cognitive skills needed in computer mediated communication as a framework for analysis. This model was used to analyze the critical thinking level of participants' blog content. The CUTIM divides the indicators as R (Relevance), I (Importance), N (Novelty), O (bringing Outside knowledge/experience), A (Ambiguities), L (Linking ideas, interpretation), J (Justification), C (Critical assessment), P (Practical utility), and W (Width of understanding). There may be two letters for more detailed indicators under each of these major categories. The symbols + and - are used at the end of each letter to identify critical and uncritical thinking respectively (Newman, Webb, \& Cochrane, 1995).

The coding unit was single topic, or message. There are various available options for unit of analysis, including, though not limited to, sentence, paragraph and message. The unit of analysis was not selected arbitrarily, but rather was chosen deliberately to align with the intent of the research. Aviv, Erlich, Ravid, and Geva, (2003) analyzed transcripts by message in order to focus on the collaborative process in discussion forums. Messages that included more than one behavior type were dual-coded. Gorsky (2011) along with fellow researchers (2009; 2010; 2011) also assigned multiple categories to messages, electing to use this unit in their study on social presence, cognitive presence, and teaching presence in discussion forums. The message unit afforded them a high-level overview of the nature of discussion in course forums as well as strong inter-rater reliability. This study was concerned with the level of thinking in blog posts; as such, the entire expressed thought, or message, was the most appropriate unit to assess the level of thought. As in the previously cited studies, the messages in this study often necessitated the assignment of more than a single code. CUTIM, the method developed and tested by Newman, Webb, and Cochrane (1995), allowed for this while analyzing the key construct (i.e., level of thinking) for the appropriate unit of analysis. A coding example can be found in Table 1, in which the first sentence was considered uncritical because it did not have the blogger's explanation of the statement. On the contrary, the following sentence was marked critical because the blogger listed advantages of using this particular tool in the classroom.

\section{Table 1. A Coding Example}

We used Twiducate, which was pretty cool (L-). Its functions are basic, but, as we saw in class, it can be effectively used for sharing ideas between classmates and as a fun way to communicate and interact (JS+). My only issue was that it was SO SLOW. But after a while, it got a little faster $(\mathrm{OP}+)$. We also learned about Webquest, which we will use for our next project. I like the idea of the project, but it appears that it will be difficult for me as a math teacher $(\mathrm{OP}+)$. Math is arguably the most difficult content area to relate to daily life and to make interesting. But I believe I am up for the challenge (JS+).

* + means critical thinking indicator, - means uncritical thinking indicator

Blog one was chosen and analyzed by two coders (the first and second author) independently. The two coders then compared and discussed their coding results, and came to an agreement on codes that were controversial. They then continued coding the remaining ten blogs as well as the peer comments independently. After all other blogs were coded; the two coders again compared results and reconciled minor differences. 
Descriptive analysis was conducted on the survey responses. Participants' self-reported time spent on each blog entry and levels of thinking before and after peer commenting were compared. Results of the open-ended questions were analyzed for themes of participants' general experience with this blogging activity, attitudes toward peer commenting, reasons for any differences regarding time spent and levels of thinking on each blog entry and their planned usage of blogging in their future classrooms.

The second author conducted the focus group and transcribed it. The interview transcript was analyzed by the first and second author for major themes of participants' attitudes toward interactive blogging and the potential uses of blogging in their future classrooms.

\section{Blog content}

\section{Results}

A Wilcoxon test was conducted to evaluate whether participants wrote more under the condition of peer commenting (Table 2). The mean of total words for each blog before peer commenting was 206.64, while the mean of total words for each blog after peer commenting was 185.36. The Wilcoxon test results indicates that students did not write significantly more when their peers were reading and commenting on their blogs, $z=-1.511, p=0.131$ (Table 3).

Table 2. Descriptive Statistics

\begin{tabular}{llllll}
\hline \hline & $\mathrm{N}$ & Mean & Std. Deviation & Minimum & Maximum \\
\hline WordsBefore & 11 & 206.64 & 132.307 & 104 & 551 \\
WordsAfter & 11 & 185.36 & 118.954 & 88 & 523 \\
\hline \hline
\end{tabular}

Table 3. Test Statistics ${ }^{b}$

Z

Asymp. Sig. (2-tailed)
Words After-Words Before

$-1.511^{a}$

.131

\section{a. Based on positive ranks. \\ b. Wilcoxon Signed Ranks Test}

The number of critical thinking indicators and uncritical thinking indicators were counted to calculate the ratio as shown in Table 4. The number of critical thinking indicators and uncritical thinking indicators in each blog for each student were counted respectively before and after peer commenting. The ratio between critical and uncritical thinking indicators without peer commenting was 2 , while the ratio between critical and uncritical thinking indicators with peer commenting was 1.8 (Table 4). 
Table 4. Numbers of Critical and Uncritical Thinking Indicators

\begin{tabular}{l|l|l|l|l|l|l}
\hline Participant & $\begin{array}{l}\text { Total Number Indicators } \\
\text { before Peer Commenting }\end{array}$ & \multicolumn{2}{l|}{$\begin{array}{l}\text { Total Number Indicators } \\
\text { after Peer Commenting }\end{array}$} & \multicolumn{2}{l}{$\begin{array}{l}\text { Ratio } \\
\text { (Critical/Uncritical) }\end{array}$} \\
\cline { 2 - 7 } & Critical & Uncritical & Critical & Uncritical & Before & After \\
\hline 1 & 47 & 7 & 29 & 6 & 6.7 & 4.8 \\
\hline 2 & 28 & 3 & 27 & 7 & 9.3 & 3.9 \\
\hline 3 & 25 & 2 & 20 & 2 & 12.5 & 10 \\
\hline 4 & 16 & 10 & 18 & 5 & 1.6 & 3.6 \\
\hline 5 & 4 & 10 & 5 & 2 & 0.4 & 2.5 \\
\hline 6 & 13 & 17 & 56 & 27 & 0.8 & 2.1 \\
\hline 7 & 15 & 9 & 6 & 8 & 1.7 & 0.8 \\
\hline 8 & 12 & 3 & 8 & 12 & 4 & 0.7 \\
\hline 10 & 4 & 16 & 9 & 16 & 0.25 & 0.6 \\
\hline 11 & 6 & 18 & 3 & 15 & 0.3 & 0.2 \\
\hline Total & 24 & 2 & 11 & 6 & 12 & 1.8 \\
\hline & 194 & 97 & 192 & 106 & 2 & 1.8 \\
\hline
\end{tabular}

Another Wilcoxon test was run to determine whether the ratio of critical thinking indicators to uncritical thinking indicators in participants' blogs changed before and after peer commenting occurred. The descriptive statistics (Table 5) show that there were seven negative ranks, which means seven participants had lower ratios of critical thinking indicators to uncritical thinking indicators after peer commenting occurred. The Wilcoxon test results indicated that participants did not increase critical thinking with the implementation of peer commenting, $z=$ $-1.245, p=0.213$ (Table 6).

Table 5. Descriptive Statistics: Ranks

\begin{tabular}{lllll}
\hline \hline & & $\mathrm{N}$ & Mean Rank & Sum of Ranks \\
\hline After - Before & Negative Ranks & $7^{\mathrm{a}}$ & 6.71 & 47.00 \\
& Positive Ranks & $4^{\mathrm{b}}$ & 4.75 & 19.00 \\
& Ties & $0^{\mathrm{c}}$ & & \\
& Total & 11 & & \\
\hline \hline
\end{tabular}
a. After < Before
b. After $>$ Before
c. After $=$ Before

Table 6. Wilcoxon Test Results: Test Statistics ${ }^{\mathrm{b}}$

\begin{tabular}{ll}
\hline \hline & After - Before \\
\hline$Z$ & $-1.245^{\mathrm{a}}$ \\
Asymp. Sig. (2-tailed) & .213 \\
\hline \hline
\end{tabular}

a. Based on positive ranks.

b. Wilcoxon Signed Ranks Test 
The two Wilcoxon tests showed that there was no statistically significant difference in terms of effort and critical thinking between the two conditions.

\section{Survey}

The survey addressed participants' self-reported technology skills and prior knowledge of blogs. Eight participants chose their technology skill as intermediate while only one was a selfreported expert. When asked whether they had read other blogs before taking the class, eight participants reported yes and one responded negatively. Six out of the eight participants, who had read other blogs before, reported they read blogs on the topics and activities of interest, such as fictional stories, favorite musicians and writers, interesting opinionated blogs, traveling information and their friends' content. One participant used blogs for lesson plan ideas and the other used blogs for research. Three out of the nine participants had their own blogs before taking the class. One considered Facebook as a blogging platform and reported writing on Facebook for others to read. One reported maintaining a blog for vacation information for a brief time before abandoning it. The third participant published original fictional writings on a blog but changed publishing platforms because the blog did not have many readers or comments.

The survey also contained items on time spent on each blog entry as well as self-reported critical thinking levels before and after peer commenting. One participant reported five more minutes and one participant reported two more minutes spent on each blog entry after knowing there were peers would be reviewing and commenting on the blog. The rest of the participants all reported consistent amount of time spent on every blog entry throughout the quarter. The two participants who reported spending more time on entries that would receive peer comments answered one unit higher for critical thinking (a five-unit level was used in the survey) after peer commenting, while the rest of the participants reported unchanging levels of thinking.

One of the open-ended questions in the survey solicited for a rationale for the change (or lack thereof) in critical thinking levels between the two situations. One participant who spent more time on each blog entry and reported higher-level thinking after peer commenting wrote:

I feel like if someone is commenting on my blog I want to make sure that my level of thinking is higher than it was before, so that I keep informing them on the information that is being talked about.

On the contrary, two participants reported that, for them, blogging was for personal benefit, explaining that they were not trying to engage readers nor did they care about comments. One participant indicated that the blogs and comments were simply assignments to complete, rather than an activity of genuine interest. This participant also offered that, if (s)he were really passionate about blog writing, there would likely have been a difference concerning the time spent on blog as well as levels of thinking. One participant stated:

It didn't make a difference to me. I discovered once the other students started commenting on my blog and I started reading theirs that I was putting a lot more effort into mine than they were into theirs, but that didn't change how I approached the 
assignment. I like to write and I like to share my thoughts, and the blog provided me with a place to do both.

The survey had additional open-ended questions asking participants about their general experience of the blogging assignment. Two participants considered writing blogs as a helpful approach to record what they learned in class, to complete their portfolio assignment and to incorporate technology in their future classrooms. One participant described that writing blogs was a worthwhile pursuit and a good habit to maintain. Three replied the blog content written for the course was not interesting. One of them suggested there should be a specific issue or topic each week for everyone to address. One considered blogs as a place for people "to share their feelings about a certain topic".

The participants were asked how they were going to use blogs in their future teaching. Seven participants stated they intend to use blogs in their classrooms. One participant who stated "it is difficult to incorporate blogs into a pre k-grade 3 classroom" suggested they might use blogs to communicate with parents. Three other participants similarly indicated that they would maintain a blog to communicate and interact with students/parents about school activities, class content, and upcoming assignments. Other potential usages offered by participants were to use blogs as a learning management system, discussion board and collaborative tool. Respondents mentioned letting students turn in their assignments, discuss class topics, provide feedback after class, and work collaboratively on projects via blogs.

\section{Focus Group}

Participants stated reasons why their attitudes changed or did not change before and after peer commenting. Three participants mentioned at different places in the interview that they used the blogs as notes to keep track of the technologies learned in class and that they felt it unnecessary to comment on each other's notes. When asked whether things would be different if they were writing their own blogs outside of the class, participants replied yes, because in that case, they would put things they are interested in on the blog and they would choose blogs that interested them to read and make comments. A major theme from the interview was, as one participant pointed out, "Creating the blog worked but commenting on each other's blog[s] wasn't necessary".

When asked in the focus group session, participants offered similar responses to survey data regarding blogs in their future classrooms; they indicated that blogs could be used as a place for students to discuss specific topics, to write journals before coming to class, to work together on math problems, and to inform parents about what was happening in school. Two participants mentioned they would use blogs as an interactive environment, in which students could write posts and comment on others' posts. One suggested that to avoid a situation in which students write individual blogs with the same opinion, the instructor could create one blog and ask everyone to write and comment on it.

\section{Discussion}

This study examined students' attitudes toward blogging for teaching and learning and explored the effect of peer comments on students' critical thinking. Results indicate that the participants' levels of thinking remained constant, regardless of the presence or absence of 
peer feedback. The Wilcoxon test results show that there was no statistically significant difference in words per blog with or without peer commenting.

One possible explanation for these results, as indicated by participants, is that most participants used their blogs to keep record of the technologies they learned in class. The blogs were more like personal journals, in which the bloggers did not bring up questions or discussion topics or controversial issues. This is consistent with the findings of Park, Heo, and Lee's study (2011), which revealed that adult learners considered blogging as self-directed and they were aware of the personal learning benefits blogging provided, but not clear on the learning community perspective of blogging. Several interviewees mentioned how they treated the blog during the quarter: "It was just like second notes for the class. So...we were just taking notes on the technology we use." "The type of blog we wrote was to record what type of technology we use. So, it was more of a note taking type of blog." Although instructions were given on what they should include in their blogs at the beginning of the quarter, several participants only recorded the tools learned in class without discussing the possible applications of them in the blogs.

Another potential reason, mentioned by participants in the survey and the interview, is that they were not interested in the content. Similar results indicating that blogging topic of interest matters to students can be found in the research conducted by Freeman and Brett (2012). To some of the participants, blogging and peer commenting were simply compulsory course tasks, not something they were interested in or passionate about. One participant explained why (s)he believed there were no differences regarding the thinking levels and time spent on each blog:

I think the real reason why I found there to be no difference is because we wrote and commented on these blogs to complete an assignment, not because we were really interested in what we were writing. The situation would be different if this was related to something about which we were really passionate.

One interviewee from the focus group interview stated: "I think commenting was unnecessary. It would be more effective if it were something that we were all passionate about. For me, I was commenting because I had to; not because I was interested in what the person said."

To avoid restrictions on participants' blog content and commenting type, the instructor did not provide detailed rubrics on what they needed to include in their comments. This might be another reason why participants thought commenting unnecessary. It would not increase participants' level of critical thinking or understanding when reading comments like "this is a great point!" or "I like your idea." This is consistent with Xie, Ke, and Sharma's (2007) study, in which the authors assumed that poor quality peer comments could be the reason why peer commenting negatively affected critical thinking. In addition, because one aim of this study was to explore the effects of peer commenting, the instructor did not serve as a commenting or discussion facilitator. Studies have shown that instructors' comments are helpful in promoting students' deeper understanding and higher-level thinking (Lu \& Jeng, 2006; Hew, Cheung, \& Ng, 2010).

Based on the above discussion and existing research, the following methods and strategies on how to use blogs in the classroom are provided. 
1. Provide detailed instructions and rubrics on writing one's own blog and on commenting on others' blogs, especially with regard to negative comments (Ellison \& $\mathrm{Wu}, 2008)$. This should decrease the possibility of students treating the blog only as a way to keep notes for themselves and to avoid shallow comments without further explanation or discussion.

2. Suggest multiple creative ways of writing to increase students' interest (Fessakis, Tatsis, \& Dimitracopoulou, 2008). For example, instead of requiring students to write what they learned in class in a narrative way, they could have the opportunity to design a course or series of lessons that integrate the new tools addressed in class. They may need to provide a rationale for their choices, identify potential problems and provide strategies for addressing these issues.

3. Encourage collaborative work among students using blogs. One participant from this study mentioned in the survey that it would have been interesting if everyone was given the same topic each week to discuss and to exchange ideas. Another participant recommended having all students write entries and comment in one blog for increased collaboration. Huang, Huang, and Yu (2011) state that students, especially from cultures that are not comfortable critiquing others, may benefit from using blogs to review peers' work. Various ways to encourage collaboration by using blogs can be adopted, such as creating group blogs, conducting peer review and designing a conversational group project using blogs.

4. Build rapport within groups and the whole class (Churchill, 2009). Dallimore, Hertenstein, and Platt (2004) suggest that faculty build supportive class environments in order to increase class discussion. McConnell (1999) also addresses the importance of supportive learning environments to students' deep learning. Therefore, instructors need to create a supportive and collaborative class for students, both physical classrooms and virtual environments.

5. Assign a 'comment facilitator' role. The comment facilitator role could be assigned to certain students (Wang, 2008; Lim, Cheung, \& Hew, 2011), or the instructor herself could serve the role in order to promote deeper thinking and to move the discussion forward (Chong, 2010). This facilitating role is common in online discussions, both synchronously and asynchronously. (Lim, Cheung, \& Hew, 2011; Levin, He, \& Robbins, 2006)

6. Promote critical thinking in different ways based on content. Based on the blog content coding, there were a lot of JP (proof or examples), JS (advantages and disadvantages of situation), and $\mathrm{P}$ (possible solution or practical usage) indicators (Newman, Webb, \& Cochrane, 1995, pp. 6-8). Other topics may naturally yield different indicators.

One limitation of the current study is the small sample size. There were only eleven participants in the study, and only nine completed the survey and the focus group interview. All participants were from one technological application class in one quarter. Further research should be conducted in a larger context with more participants. Another limitation is that the study only lasted for eight weeks, with students blogging once per week. Future studies could be designed for an extended duration not only to generate more data, but to probe attitude and levels of thinking across time and experience. 


\section{Acknowledgement}

The authors would like to thank Dr. John Henning at Ohio University for his encouragement and valuable input for this article.

\section{References}

Alexander, B. (2006). Web 2.0: A new wave of innovation for teaching and learning? Educause Review, 41(2), 32-44. Retrieved on December 30, 2011 from http://www.educause.edu/ ir/library/pdf/erm0621.pdf.

Aviv, R., Erlich, Z., Ravid, G., \& Geva, A. (2003). Network analysis of knowledge construction in asynchronous learning networks. Journal of Asynchronous Learning Net-works, 7(3), 123.

Blood, R. (2000). Weblogs: A history and perspective. Retrieved on June 26, 2012 from http://www.rebeccablood.net/essays/weblog_history.html

Chong, E. K. (2010). Using blogging to enhance the initiation of students into academic research. Computers \& Education, 55(2), 798-807. doi:10.1016/j.compedu.2010.03.012

Chu, S. K. W., Chan, C. K. K., \& Tiwari, A. F. Y. (2012). Using blogs to support learning during internship. Computers \& Education, 58(3), 989-1000.

Chu, S. K., Kwan, A. C., \& Warning, P. (2012). Blogging for information management, learning, and social support during internship. Educational Technology \& Society, 15(2), 168-178.

Churchill, D. (2009). Educational applications of Web 2.0: Using blogs to support teaching and learning. British Journal of Educational Technology, 40(1), 179-183.

Coutinho, C. P. (2007). Cooperative learning in higher education using weblogs: A study with undergraduate students of education in Portugal. Proceedings of the 5th International Conference on Education and Information Systems, Technologies and Applications (EISTA) (pp. 60-64). Orlando: EUA. Julho.

Creswell, J. W. (2013). Qualitative inquiry and research design: Choosing among five approaches. Los Angeles: Sage.

Dallimore, E. J., Hertenstein, J. H., \& Platt, M. B. (2004). Classroom participation and discussion effectiveness: Student-generated strategies. Communication Education, 53(1), 103-115.

Deng, L., \& Yuen, H. K. (2011). Toward a framework for educational affordances of blogs. Computers \& Education, 56(2), 441-451.

Ellison, N., \& Wu, Y. (2008). Blogging in the Classroom: A Preliminary exploration of student attitudes and impact on comprehension. Journal of Educational Multimedia and Hypermedia, 17(1), 99-122.

Fessakis, G., Tatsis, K., \& Dimitracopoulou, A. (2008). Supporting "learning by design" activities using group blogs. Journal of Educational Technology \& Society, 11(4), 199-212.

Freeman, W. \& Brett, C. (2012). Prompting authentic blogging practice in an online graduate course. Computers \& Education, 59(3), 1032-1041.

Garrison, D. R. (1992) Critical thinking and self-directed learning in adult education: An analysis of responsibility and control issues. Adult Education Quarterly, 42(3), 136-148. 
Good, J. M. \& Whang, P. A. (2002). Encouraging reflection in pre-service teachers through response journals. The Teacher Educator, 37(4), 254-267.

Gorsky, P. (2011). Hidden structures in asynchronous course forums: Toward a golden ratio population parameter. Proceedings of Ninth International Conference on Computer Supported Collaborative Learning: Connecting Computer Supported Collaborative Learning to Policy and Practice. Center for Information Technology in Education, University of Hong Kong.

Gorsky, P., \& Blau, I. (2009). Effective online teaching: A tale of two instructors. International Review of Research on Distance Learning, 10(3). Retrieved on October 29, 2012 from http://www.irrodl.org/index.php/irrodl/article/view/712/1270

Gorsky, P., Caspi, A., Antonovsky, A., Blau, I., \& Mansur, A. (2010). The relationship between academic discipline and dialogic behavior in Open University course forums. International Review of Research on Distance Learning, 11(2). Retrieved on October 29, 2012 from http://www.irrodl.org/index.php/irrodl/article/view/820/1546

Gorsky, P., Caspi, A., \& Blau, I. (2011). Communities of inquiry in higher education asynchronous course forums: Toward a population parameter. Manuscript submitted for publication.

Halic, O., Lee, D., Paulus, T., \& Spence, M. (2010). To blog or not to blog: Student perceptions of blog effectiveness for learning in a college-level course. The Internet and Higher Education, 13, 206-213.

Henri, F. (1991) Computer conferencing and content analysis, In C. O'Malley (ed.), Computer Supported Collaborative Learning. Heidelberg: Springer-Verlag.

Hew, K., Cheung, W., \& Ng, C. (2010). Student contribution in asynchronous online discussion: a review of the research and empirical exploration. Instructional Science, 38(6), 571606. doi:10.1007/s11251-008-9087-0

Huang, T. C., Huang,, Y. M., \& Yu, F. Y. (2011). Cooperative weblog learning in higher education: Its facilitating effects on social interaction, time lag, and cognitive load. Educational Technology \& Society, 14(1), 95-106.

Hurlburt, S. (2008). Defining tools for a new learning space: writing and reading class blogs. Journal of Online Learning and Teaching, 4(2). Retrieved on December 30, 2011, from http://jolt.merlot.org/vol4no2/hurlburt0608.htm

Lenhart, A., Simon, M., \& Graziano, M. (2001). The Internet and Education: Findings of the Pew Internet \& American Life Project. Pew Internet \& American Life Project, Washington, DC. Retrieved on December 30, 2011 from http://www.eric.ed.gov/ERICWebPortal/ contentdelivery/servlet/ERICServlet?accno=ED457849

Levin, B. B., He, Y., \& Robbins, H. H. (2006). Comparative analysis of preservice teachers' reflective thinking in synchronous versus asynchronous online case discussions. Journal of Technology and Teacher Education, 14(3), 439-460.

Lim, S. C., Cheung, W. S., \& Hew, K. F. (2011). Critical thinking in asynchronous online discussion: An investigation of student facilitation techniques. New Horizons in Education, 59(1), 52-65.

Loving, C. C., Schroeder, C., Kang, R., Shimek, C., \& Herbert, B. (2007). Blogs: Enhancing links in a professional learning community of science and mathematics teachers. Contemporary Issues in Technology and Teacher Education , 45(4), 323-333. 
Lu, L. L., \& Jeng, I. (2006). Knowledge construction in inservice teacher online discourse: Impacts of instructor roles and facilitative strategies. Journal of Research on Technology in Education, 39(2), 183-202.

McConnell, D. (1999). Examining a collaborative assessment process in networked lifelong learning. Journal of Computer Assisted Learning, 15(3), 232-243.

Nelson, J., Christopher, A., \& Mims, C. (2009). TPACK and Web 2.0: Transformation of teaching and learning. TechTrends: Linking Research \& Practice to Improve Learning, 53(5), 80-87. doi:10.1007/s11528-009-0329-z

Newman, D. R., Webb, B., \& Cochrane, C. (1995). A content analysis method to measure critical thinking in face-to-face and computer supported group learning. Interpersonal Computing and Technology, 3(2), 56-77.

Park, Y., Heo, G. M., \& Lee, R. (2011). Blogging for informal learning: Analyzing bloggers' perceptions using learning perspective. Educational Technology \& Society, 14(2), 149160.

Pinkman, K. (2005). Using blogs in the foreign language classroom. JALT CALL Journal , 1(1), 1224.

Scheidt, L. A. (2009). Diary weblogs as genre (Doctoral dissertation). Retrieved on December 30, 2011 from http://citeseerx.ist.psu.edu/viewdoc/download?doi=10.1.1.154.3724 \&rep=rep1\&type=pdf

Shoffner, M. (2008). Informal reflection in pre-service teacher education. Reflective Practice, 9(2), 123-134.

Sim, J. W. S., \& Hew, K. F. (2010). The use of weblogs in higher education settings: A review of empirical research. Educational Research Review, 5(2), 151-163.

Stefanac, S. (2006). Dispatches from blogistan: A travel guide for the modern blogger. Berkeley, CA: New Riders.

Wang, Q. (2008). Student-facilitators' roles in moderating online discussions. British Journal of Educational Technology, 39(5), 859-874.

Weerkamp, W. \& de Rijke, M. (2008). Credibility improves topical blog post retrieval. In Proceedings of the $46^{\text {th }}$ Annual Meeting of the Association for Computational Linguistics: Human Language Technologies (ACL-08: HLT) (pp. 923-931). Stroudsburg, PA: Association for Computational Linguistics.

Williams, J. B. \& Jacobs, J. (2004). Exploring the use of blogs as learning spaces in the higher education sector. Australasian Journal of Educational Technology, 20(2), 232-247.

Xie, Y., Ke, F., \& Sharma, P. (2007). The effect of peer feedback for blogging on college students' reflective learning processes. The Internet and Higher Education, 11(4), 18-25.

Xie, Y., Ke. F. \& Sharma, P. (2010). The effect of peer-interaction styles in team blogging on students' cognitive thinking and blog participation. Journal of Educational Computing Research. 42(4), 459-479.

Yang, S.-H. (2009). Using blogs to enhance critical reflection and community of practice. Educational Technology \& Society, 12(2), 11-21. 
Yang, C. \& Chang, Y. S. (2012). Assessing the effects of interactive blogging on student attitudes toward peer interaction, learning motivation, and academic achievements. Journal of Computer Assisted Learning, 28(2), 126-135.

Zeng, X. \& Harris, S. T. (2005). Blogging in an online health information technology class. Perspectives in Health Information Management. 2:6. Retrieved on February 26, 2012 from http://www.ncbi.nlm.nih.gov/pmc/articles/PMC2047310/.

Correspondence: Kun Li, Doctoral Candidate, Instructional Technology Program, The Gladys W. and David H. Patton College of Education, Ohio University, Athens, Ohio, United States 